\title{
ОЦЕНКА ИНВЕСТИЦИОННОЙ ДЕЯТЕЛЬНОСТИ РОССИЙСКИХ МЕТАЛЛУРГИЧЕСКИХ ПРЕДПРИЯТИЙ В 2017-2019 ГОДАХ
}

\section{(C) 2020 Мажанская Елизавета Владимировна}

бакалавр, студент магистратуры кафедры «Экспертиза и управление недвижимостью»

Сибирский федеральный университет, Россия, Красноярск

E-mail: mazhanskaya97@mail.ru

(c) 2020 Пасечник Анастасия Сергеевна

студент специалитета кафедры «Строительство уникальных зданий и сооружений»

Сибирский федеральный университет, Россия, Красноярск

E-mail: pasechnicnastya14@mail.ru

(C) 2020 Беккер Мария Станиславовна

студент специалитета кафедры «Строительство уникальных зданий и сооружений»

Сибирский федеральный университет, Россия, Красноярск

E-mail: mary.bekker.98@mail.ru

(c) 2020 Полегенько Анастасия Валерьевна

студент специалитета кафедры «Строительство уникальных зданий и сооружений»

Сибирский федеральный университет, Россия, Красноярск

E-mail: apolegenko@inbox.ru

\section{(c) 2020 Родионенко Евгения Викторовна}

студент бакалавра кафедры «Промышленное и гражданское строительство»

Сибирский федеральный университет, Россия, Красноярск

E-mail: rodionaaaa@mail.ru

В рамках данной научной статьи осуществляется анализ инвестиционной деятельности ключевых металлургических компаний Российской Федерации. Производится оценка финансовых результатов в сфере инвестиционной деятельности металлургических компаний. Формируются выводы относительно причин, повлиявших на результаты инвестиционной деятельности отдельных компаний отечественного металлургического комплекса.

Ключевые слова: инвестиции, инвестиционная деятельность, металлургические предприятия, инвестиции в финансовые активы, инвестиции в материальные активы.

В рамках современной глобализации мирохозяйственных связей и все большего влияния новых технологий на эффективность операционной деятельности промышленных компаний, особо важную роль играет эффективная инвестиционная деятельность. Данное направление деятельности компании позволяет обеспечивать должный уровень конкурентных преимуществ в рамках модернизация производственных процессов. Металлургический комплекс РФ играет важную роль в системе обеспечения должного уровня экономической безопасности государства [4], следовательно, можно выделить особую важность эффективной инвестиционной деятельности в рамках развития компаний отечественного металлургического комплекса, что и обуславливает актуальность темы данного научного исследования.

В условиях внешнеэкономического и внешнеполитического противостояния, а также потенциального мирового экономического кризиса, существует острая необходимость поддержания должного уровня развития ключевых отраслей национальной экономики, которые обеспечивают значительную долю в ВВП и поступлениях в бюджеты всех уровней [3]. Одной из таких отраслей является металлургический комплекс РФ, развитие которого в условиях санкций возможно лишь при условии эффективной инвестиционной деятельности в рамках технологического и инновационного развития компаний отрасли [2]. 
Ряд современных ученых отмечают необходимость активизации процессов в сфере развития компаний отечественного металлургического комплекса в среднесрочном периоде, с целью повышения уровня рыночной капитализации компании с одной стороны и увеличения уровня конкурентных преимуществ с другой стороны (Таблица 1).

Как можно увидеть из таблицы 1 , эксперты рассматривают в качестве преимущественного развития процессов в сфере инвестиционной деятельности металлургических компаний Российской Федерации направленность в рамках достижения стабильного опережающего роста рыночной стоимости компаний наряду со стабильным ростом доходности. Активизация процессов в рамках инвестиционной деятельности должно обеспечить существенный уровень независимости компаний относительно зарубежных технологий в системе развития отечественного комплекса НИОКР.

В рамках предметного раскрытия тематики данного научного исследования осуществим анализ результатов инвестиционной деятельности ведущих компаний металлургического комплекса Российской Федерации (Таблица 2).

Как можно увидеть из таблицы 2 , за анализируемый временной период произошли следующие трансформации и преобразования в системе результатов инвестиционной деятельности компаний металлургического комплекса РФ:

- в динамике результатов от инвестиционной деятельности ПАО «Северсталь» прослеживается четкая тенденция к уменьшению

Таблица 2. Анализ результатов инвестиционной деятельности отдельных металлургических компаний РФ (млрд. рублей) в 2017-2019 годах [5-7]

\begin{tabular}{|c|c|c|c|c|}
\hline \multirow{3}{*}{ Год } & Показатель & \multicolumn{3}{|c|}{ Компании } \\
\cline { 3 - 5 } & ПАО «Северсталь» & $\begin{array}{c}\text { ПАО «Магнитогор- } \\
\text { ский металлурги- } \\
\text { ческий комбинат» }\end{array}$ & ПАО «НЛМК» \\
\hline \multirow{3}{*}{2017} & Поступления & 130,1 & 12,1 & 37,5 \\
\hline \multirow{3}{*}{2018} & Платежи & 19,17 & 38,9 & 25,09 \\
\cline { 2 - 5 } & Сальдо & 110,93 & $-26,8$ & 12,41 \\
\hline \multirow{3}{*}{2019} & Поступления & 84,88 & 2,77 & 113,65 \\
\cline { 2 - 5 } & Платежи & 15,87 & 42,52 & 42,05 \\
\cline { 2 - 5 } & Сальдо & 69,01 & $-39,75$ & 71,6 \\
\hline & Поступления & 58,89 & 8,17 & 85,55 \\
\cline { 2 - 5 } & Платежи & 40,42 & 40,92 & 60,1 \\
\cline { 2 - 5 } & Сальдо & 18,47 & $-32,75$ & 25,45 \\
\hline
\end{tabular}

Таблица 1. Целевые ориентиры инвестиционного развития компания металлургического комплекса РФ в период с 2020 по 2030 г. [1]

\begin{tabular}{|l|l|l|l|}
\hline \multicolumn{1}{|c|}{ Показатель } & \multicolumn{1}{|c|}{2020} & \multicolumn{1}{|c|}{2025} \\
\hline Технологии & $\begin{array}{l}\text { Достижение пиковой } \\
\text { производительности в } \\
\text { рамках эффективного } \\
\text { использования наличе- } \\
\text { ствующих ресурсов }\end{array}$ & $\begin{array}{l}\text { Развитие инновационных } \\
\text { технологий собственного } \\
\text { производства в рамках } \\
\text { политики «импортозаме- } \\
\text { щения» }\end{array}$ & $\begin{array}{l}\text { Развитие инновационных } \\
\text { пения бизнес-процессами } \\
\text { и эффективным исполь- } \\
\text { зованием ресурсов }\end{array}$ \\
\hline Менеджмент & $\begin{array}{l}\text { Обеспечение эффектив- } \\
\text { ного управления финан- } \\
\text { совыми потоками }\end{array}$ & $\begin{array}{l}\text { Увеличение роли инве- } \\
\text { стиционной деятельности }\end{array}$ & $\begin{array}{l}\text { Обеспечение увеличения } \\
\text { роли инвестиционно- } \\
\text { ности }\end{array}$ \\
\hline Финанноной деятель- \\
\hline Тенденции
\end{tabular}


положительного сальдо денежных потоков от инвестиционной деятельности. Если в 2015 году результат, составляя $+110,93$ млрд. рублей, то по итогам 2019 года всего, лишь +18,47 млрд. рублей. Во многом это было обусловлено снижением объемов поступлений от инвестиционной деятельности и ростом затрат на инвестиционные проекты. Рост затрат в рамках инвестиционной деятельности вырос за счет увеличение финансирования проектов в рамках модернизации и создания новых основных фондов. В то же время снижение объемов поступлений от инвестиционной деятельности было обусловлено поступательным сокращением выплат, по облигациям, приобретенным компанией в 2013-14 годах, для стабилизации финансового портфеля;

- в динамике результатов от инвестиционной деятельности ПАО «Северсталь» прослеживается четкая тенденция к увеличению отрицательного сальдо денежных потоков от инвестиционной деятельности, с -26,8 млрд. рублей в 2017 году до -32,75 млрд. рублей по итогам 2019 года. В значительно степени данный результата был обусловлен ростом вложений в модернизацию, переоборудование и приобретение новых основных фондов компанией. Ко всему прочему компания не использует значительный объем собственного капитала для инвестирования в финансовые активы, что во многом и обуславливает отрицательный поток от инвестиционной деятельности;

- в динамике результатов от инвестиционной деятельности ПАО «НЛМК» прослеживается четкая тенденция к росту положительного сальдо денежных потоков от инвестиционной деятельности, с 12,4 млрд. рублей в 2017 году до 25,45 млрд. рублей по итогам 2019 года соответственно. Во многом это обуславливается опережающим ростом поступлений от инвестирования в финансовые активы относительно инвестиционных затрат.

Как итог данного научного исследования можно сделать следующие выводы:

- совершенствование процессов инвестиционной деятельности металлургических компаний РФ является важным элементом в системе обеспечения долгосрочного и эффективного функционирования данных компаний, а также обеспечения должного уровня экономической безопасности РФ;

- по мнению многих современных авторов, инвестиционные процессы металлургических компаний РФ должны быть направлены на долгосрочный рост рыночной стоимости бизнеса, а также опережающий рост технологического развития в рамках системы «импортозамещения»;

- произведенный анализ инвестиционной деятельности ключевых металлургических компаний РФ дает возможность понять, что все они проводят эффективную инвестиционную политику в системе эффективного развития, однако при этом необходимо отметить следующие особенности. ПАО «Северсталь» ориентируется на инвестиционную политику в рамках финансирования основных средств с одной стороны, и получения прибыли от вложения в финансовые активы с другой стороны. ПАО «ММК» в рамках собственной инвестиционной политики ориентируется преимущественно на вложения (покупку) в материальные активы предприятия. В то же время ПАО «НЛМК» ориентируется преимущественно на получение прибыли от вложения в финансовые активы, в то же время инвестирование в операционные процессы находится на относительно низком уровне.

\section{Библиографический список}

1. Буданов И.А., Устинов В.С. Взаимосвязи производственной и инвестиционной деятельности в отраслях комплекса конструкционных материалов // Проблемы прогнозирования. 2018. № 5 (170). URL: https://cyberleninka.ru/article/n/vzaimosvyazi-proizvodstvennoy-i-investitsionnoy-deyatelnosti-v-otraslyahkompleksa-konstruktsionnyh-materialov (дата обращения: 05.05.2020).

2. Петров М.В. Финансирование компаний в условиях замедления экономики и санкций // Финансы: Теория и Практика. 2018. № 3. URL: https://cyberleninka.ru/article/n/finansirovanie-kompaniy-v-usloviyahzamedleniya-ekonomiki-i-sanktsiy (дата обращения: 05.05.2020)

3. Устинов В.С. Подходы к оценке инвестиционной политики в российской металлургии // Научные труды: Институт народнохозяйственного прогнозирования РАН. 2018. № . URL: https://cyberleninka.ru/article/n/ podhody-k-otsenke-investitsionnoy-politiki-v-rossiyskoy-metallurgii (дата обращения: 05.05.2020) 
4. Шпаковская Е. П., Чинаева Т.И., ЛарионоваЕ.И. Статистический анализ деятельности металлургического сектора // Большая Евразия: Развитие, безопасность, сотрудничество. 2019. № 2-1. URL: https://cyberleninka. ru/article/n/statisticheskiy-analiz-deyatelnosti-metallurgicheskogo-sektora (дата обращения: 05.05.2020)

5. ПАО ММК. Финансовая отчетность. URL: http://www.mmk.ru/for_investor/financial_statements/dynamics/ (дата обращения: 05.05.2020)

6. ПАО «Северсталь». Финансовая отчетность. URL: https://www.severstal.com/rus/ir/results_reports/finreps $\mathrm{rsbu} /$ (дата обращения: 05.05.2020)

7. ПАО «НЛМК». Финансовая отчетность. URL: https://www.e-disclosure.ru/portal/files.aspx?id=2509\&type=3 (дата обращения: 05.05.2020) 